\title{
Potassium-stimulated Purine Release by Cultured Sympathetic Neurons ${ }^{1}$
}

\author{
EVE J. WOLINSKY ${ }^{2}$ AND PAUL H. PATTERSON ${ }^{3}$ \\ Department of Neurobiology, Harvard Medical School, Boston, Massachusetts 02115
}

\begin{abstract}
Environmental factors can influence cultured sympathetic neurons to acquire several different neurotransmitter phenotypes. Cholinergic and noradrenergic transmitter status can be influenced by heart cell conditioned medium, chronic depolarization (Patterson, P. H. (1978) Annu. Rev. Neurosci. 1: 1-17), and rat serum (Wolinsky, E. J., and P. H. Patterson, (1985) J. Neurosci. 5: 1509-1512); formation of electrical synapses can be induced by insulin (Wolinsky, E. J., H. Patterson, and A. L. Willard (1985) J. Neurosci., 5: 16751679). Purine release has also been proposed as a possible transmission mode for sympathetic neurons (Potter, D. D., E. J. Furshpan, and S. C. Landis (1983) Fed. Proc. 42: 16261632), and as such, it is another candidate for environmental modulation. In this report, we assess the ability of sympathetic neuron cultures grown with and without serum to release metabolically labeled tritriated purine compounds in response to depolarization. Exposure to $54 \mathrm{~mm}$ potassium stimulated release of adenosine, inosine, and hypoxanthine from both serum-supplemented and defined-medium cultures. However, depolarization-stimulated release of adenine nucleotides was observed only from serum-supplemented cultures and not from serum-free cultures. The release of adenine nucleotides from serum-containing cultures is affected by divalent cations in the manner expected for a neurosecretory process. The failure of serum-free cultures to release detectable adenine nucleotides raises the possibility that they do not share with, or that they differ from, serum-supplemented cultures in the purinergic aspect of the multiple transmission modes available to sympathetic neurons, and that this difference may be due to effects of the culture medium.
\end{abstract}

Received July 2, 1984; Revised October 5, 1984;

Accepted October 8, 1984

\footnotetext{
${ }^{1}$ This work was supported by grants from the National Institute of Neurological Disorders and Stroke. E. J. W. was a predoctoral trainee of the National Institute of General Medical Sciences. P. H. P. was a Rita Allen Foundation Fellow and a McKnight Foundation Neuroscience Development Awardee. Support was also provided by grants from the National Institute of Neurological and Communicative Disorders and Stroke to P. H. P. We are grateful to Drs. K. Yoshioka and T. M. Jessell for sharing their data, methods, and facilities and to Dr. W. D. Matthew for providing laboratory space. We also thank Drs. S. C. Landis and T. M. Jessell for helpful discussions of the manuscript

${ }^{2}$ To whom correspondence should be sent, at her present address: Department of Biology, Massachusetts Institute of Technology, Cambridge, MA 02139

${ }^{3}$ Present address: Division of Biology, California Institute of Technology, Pasadena, CA 91125.
}

The concept of "dual" transmitter function in cultured sympathetic neurons - the secretion of both acetylcholine and norepinephrine by a single neuron-has recently been expanded to that of "multiple" function, to include possible purinergic transmission (Potter et al., 1983). This idea arose from the observation of noncholinergic inhibitory synaptic interactions between sympathetic neurons and cardiac myocytes in microcultures which can be mimicked by exogenous purine and inhibited by purinoceptor antagonists (Furshpan et al., 1981; E. J. Furshpan, D. D. Potter, and S. Matsumoto, manuscript in preparation). Neurogenic responses characterized pharmacologically as noncholinergic and nonadrenergic have also been observed in vivo in a number of tissues with sympathetic innervation. The ability of exogenously applied purines to mimic, and of purinoceptor antagonists to block, such responses in some cases suggests that they may be mediated by adenosine or adenine nucleotides (Burnstock, 1972; Sneddon et al., 1982). Thus, purinergic function may be an additional transmitter phenotype available to sympathetic neurons.

Both cholinergic and noradrenergic differentiation by cultured sympathetic neurons can be influenced by environmental factors such as heart cell conditioned medium (Patterson and Chun, 1977), chronic depolarization (Walicke et al., 1977), and rat serum (Wolinsky and Patterson, 1985). In addition, the capacity for electrical neurotransmission can be induced by treatment with insulin (Wolinsky et al., 1985b). It is therefore of interest to determine whether purinergic function can also be influenced by the culture environment. We wished to compare depolarization-stimulated purine release from cultures grown with and without serum, a factor which affects cholinergic development. Rat serum promotes cholinergic development; neurons grown in defined medium without rat serum have noradrenergic transmitter status (lacovitti et al., 1982; Wolinsky et al., 1985a).

Purine release from cultured sympathetic neurons has not been previously studied biochemically. It was therefore necessary to first characterize purine metabolism and depolarization-dependent release by conventional serum-containing cultures before comparisons with serum-free cultures could be made. Assessment of purine release in sympathetic neuron cultures has several advantages over studies on tissue preparations such as brain slices (Pull and Mcllwain, 1973; Stone, 1981) or dissected smooth muscle (Su et al., 1971; Burnstock et al., 1978). Tissue preparations contain non-neuronal cells and a heterogeneous population of neurons, while the cultured neurons are purely of sympathetic origin, and non-neuronal cells are eliminated by antimitotic treatments. The diverse roles of purines in cell metabolism must be considered in interpretation of results observed in culture, as in intact tissues, however the identity of the cells responsible is assured.

\section{Materials and Methods}

Cell culture. Newborn rat superior cervical ganglia were enzymatically dissociated as described by Wolinsky and Patterson (1983). The neurons were grown in the absence of non-neuronal cells in either serum-containing or serum-free medium (Hawrot and Patterson, 1979; Wolinsky et al., 1985a). 
Chronic depolarization with growth medium containing $20 \mathrm{mM} \mathrm{K}^{+}$was used to produce noradrenergic cultures as described by Walicke et al. (1977). In any one experiment, comparisons were made between sister cultures only.

Metabolic labeling. 2,8-[3H]Adenosine with a specific activity of $31 \mathrm{Ci} /$ $\mathrm{mmol}$ dissolved in water at a concentration of $1 \mathrm{mCi} / \mathrm{ml}$ was obtained from New England Nuclear. This stock solution was diluted 1:100 in complete L15- $\mathrm{CO}_{2}$ medium (Hawrot and Patterson, 1979), which does not contain adenosine. Serum-free cultures were labeled in N2L15 medium, as described by Wolinsky et al. (1985a). Cultures were rinsed three times with phosphatebuffered saline, and the wells containing the neurons were then incubated in either 30 or $50 \mu \mathrm{l}$ of isotopic labeling medium. The wells in which the neurons are cultured are shallow and less than $1 \mathrm{~cm}^{2}$ in area: $30 \mu$ lills this volume. Isotopic incubations were carried out at $37^{\circ} \mathrm{C}$ in a $5 \% \mathrm{CO}_{2}$ atmosphere. The isotopic incubation medium was replaced twice at 2 -hr intervals with fresh labeling medium, for a total uptake period of $6 \mathrm{hr}$. Radioactivity in aliquots of labeling medium was assayed by scintillation counting at an efficiency of $35 \%$ before and after exposure to cells. The rate of uptake and amount of radioactivity accumulated by serum-containing and serum-free sister cultures were similar. The pattern of incorporation of $\left[{ }^{3} \mathrm{H}\right]$ adenosine in serum-free and serum-supplemented cultures also appears to be similar: culture lysates from a serum-free and serum-supplemented culture analyzed by thin layer chromatography (as described below) contained similar profiles of radioactive purine compounds.

Release protocol. The incubation media for release experiments were as used by Sweadner (1981). Their composition is as follows: nondepolaring isotonic saline contains $5 \mathrm{mM} \mathrm{KCl}, 140 \mathrm{mM} \mathrm{NaCl}, 3 \mathrm{mM} \mathrm{CaCl}_{2}$, and $1.5 \mathrm{~mm}$ HEPES (Sigma), buffered to $\mathrm{pH} 7.4$ with Tris-OH (Sigma). Glass-distilled water was used. In media with different divalent cations, $\mathrm{CaCl}_{2}$ was omitted and replaced with an equal amount of $\mathrm{BaCl}_{2}$ or $\mathrm{CoCl}_{2}$. Depolarizing saline contained $54 \mathrm{~mm} \mathrm{KCl}$ and the above concentrations of the other salts, except that $\mathrm{NaCl}$ was reduced to $90 \mathrm{~mm}$. All incubations were performed at room temperature. After isotopic loading, cultures were washed four times in 3 min incubations with $50-\mu \mathrm{l}$ volumes of $5 \mathrm{mM} \mathrm{K}^{+}, \mathrm{Ca}^{++}$-containing saline. Aliquots of these washes were assayed for radioactivity by scintillation counting. The first wash contained $4 \%$ as many counts as the final application of isotopic labeling medium, and the succeeding washes contained $2 \%$. The cultures were incubated twice more in $50-\mu$ l volumes of $5 \mathrm{~mm} \mathrm{~K}{ }^{+}, \mathrm{Ca}^{++}$. containing saline, for $5 \mathrm{~min}$ each. At the end of each of these nondepolarizing incubations, $25 \mu \mathrm{l}$ of culture supernatant were removed to polypropylene Microtest tubes (Denville Scientific, 250- $\mu$ l vol) on ice containing $2 \mu \mathrm{l}$ each of glacial acetic acid. The next incubation, in depolarizing saline containing $\mathrm{Ca}^{++}, \mathrm{Co}^{++}$, or $\mathrm{Ba}^{++}$, was performed similarly. The remaining medium was removed from the culture wells, and the neurons and their collagen substrate were scraped off the plate into $25 \mu \mathrm{l}$ of depolarizing medium plus glacial acetic acid in microtest tubes on ice. The samples were stored at $-20^{\circ} \mathrm{C}$.

Thin layer chromatography. The culture supernatants and lysates obtained during the release experiments described above were analyzed by thin layer chromatography, essentially by the method of Reibel and Rovetto (1978). Five microliters of a mixture of 10 standards (adenosine $5^{\prime}$-triphosphate (ATP), adenosine $5^{\prime}$-diphophosphate (ADP), adenosine $5^{\prime}$-monophosphate (AMP), adenosine $3^{\prime}: 5^{\prime}$-monophosphate (cAMP), inosine $5^{\prime}$-monophosphate (IMP), and nicotinamide adenine dinucleotide (NAD) at a concentration of 2 $\mathrm{mM}$ and adenine, adenosine, hypoxanthine, and inosine at a concentration of $4 \mathrm{~mm}$ ) were spotted onto $\mathrm{PEI}$ cellulose thin-layer plastic-backed plates (Schleicher and Schuell no. F1440, with fluorescent minerals). The plates were then loaded with $10-\mu$ laliquots of supernatants from release incubations or $2-\mu \mathrm{l}$ samples of culture lysates. The four samples obtained from each culture during the release protocol (two nondepolarized, one depolarized, one lysate) were always analyzed on the same plate. The plates were each run in three solvent systems in the following order: 1:1:8:butanol: methanol:water, water, and $1.4 \mathrm{M} \mathrm{LiCl}$. Spots were visualized with shortwavelength ultraviolet light. The separation obtained is as follows (eight spots were resolved during chromatographic analysis, listed in order of increasing Rf): ATP, ADP, AMP, IMP, NAD, adenosine, hypoxanthine, and inosine. The AMP and IMP spots also contain some cAMP. In occasional separations, the CAMP spot was resolved individually and was found to contain less than $10 \%$ as much radioactivity as the AMP spot. Adenine comigrates with NAD in this chromatography system. The lanes were cut into $1-\mathrm{cm}$ slices which were placed in shell vials with $400 \mu \mathrm{l}$ of $1.4 \mathrm{M} \mathrm{LICl}$ and shaken on a gyrotatory platform for $1 / 2 \mathrm{hr}$ at $4^{\circ} \mathrm{C}$, after which $4 \mathrm{ml}$ of scintillation fluid (Ultrafluor National Diagnostics) were added. The counting efficiency of radioactive $\left[{ }^{3} \mathrm{H}\right]$ adenosine standard after thin-layer analysis under these conditions was $10 \%$. The radioactivity in areas of the plate without uitraviolet fluorescent material was between 10 and $30 \mathrm{cmm} / \mathrm{cm}$. This hackground level was subtracted from the radioactivity measured in each spot.
Guanosine $5^{\prime} \cdot \mathrm{di}$ - and monophosphates (GDP, GMP) are also resolved by this chromatography system. Standards for these compounds migrate to positions between the adenine nucleotides: GDP between ATP and ADP GMP between ADP and AMP. Guanosine $5^{\prime}$-triphosphate (GTP) migrates behind and somewhat overlapping ATP, between the origin and the AIP spot. The regions between the adenine nucleotides have been cut out and counted in each experiment with cultures labeled with $2,8-\left[{ }^{3} \mathrm{H}\right]$ adenosine. No radioactivity above background was detected in these areas, from chromatographs of culture supernatants or lysates. The possibility that guanine compounds are labeled in cultured sympathetic neurons during incubation with $2,8 \cdot\left[{ }^{3} \mathrm{H}\right]$ adenosine and that radioactivity from these compounds may contaminate the adenine nucleotides separated by thin-layer chromatography was also tested by using a $\left[{ }^{3} \mathrm{H}\right]$ adenosine precursor labeled only in the 2 position. The pattern of radioactive purine release observed in a serumcontaining culture using the precursor $2\left[{ }^{3} \mathrm{H}\right]$ adenosine, which loses its tritium label when ammoniated at that position to form the guanine base, was similar to that obtained from cultures labeled with $2,8-\left[{ }^{3} \mathrm{H}\right]$ adenosine. Thus, flux of radiolabeled adenosine into guanine nucleotide pools does not contribute to the released radioactivity analyzed in these experiments.

\section{Results}

The objective of the experiments described here is to determine the extent to which sympathetic neurons cultured with and without serum release metabolically labeled adenine nucleotides and/or other metabolites or adenosine during depolarization. After loading with $\left[{ }^{3} \mathrm{H}\right]$ adenosine, cultures were incubated in nondepolarizing, low potassium $\left(5 \mathrm{~mm} \mathrm{~K} \mathrm{~K}^{+}\right.$) buffer for two 5 -min periods and then in depolarizing, high potassium buffer $\left(54 \mathrm{mM} \mathrm{K} \mathrm{K}^{+}\right.$) for a final 5-min incubation. Aliquots of culture supernatants from these incubations were analyzed by thin layer chromatography to give a profile of radiolabeled compounds released into the culture fluid during the incubations. Comparison of the profiles obtained from the low and high potassium incubations is used to assess the dependence of the release of specific compounds on depolarization. At the termination of the experiment, the neurons were lysed, and the lysates were also analyzed by thin layer chromatography to determine the profile of intracellularly stored derivatives of $\left[{ }^{3} \mathrm{H}\right]$ adenosine.

The information obtained by the above procedures from one serum-containing culture is shown in Figure 1. Uptake of $\left[{ }^{3} \mathrm{H}\right]$ adenosine is shown in Figure $1 \mathrm{~A}$ as radioactivity removed from the incubation medium during a 6 -h period; removal was approximately linear. The neurons removed $67 \%$ of the total radioactivity applied during the isotopic incubation. Incorporation of $\left[{ }^{3} \mathrm{H}\right]$ adenosine into intracellular adenine nucleotides is shown in Figure $1 B$. The difference in counts per minute of intracellular radioactivity measured by depletion of the isotopic incubation medium (Fig. 1A) and thin layer chromatographic separation of culture lysate is due to incomplete elution of labeled compounds from slices of the thin layer chromatography plate prior to scintillation counting and additional reduction of counting efficiency due to the presence of the nontransparent slices of the thin layer plate during counting. Most of the recovered radioactivity is associated with adenine nucleotides. Upon entering the cells by facilitated diffusion, $\left[{ }^{3} \mathrm{H}\right]$ adenosine is a substrate for successive phosphorylations via the enzymes adenosine kinase, adenylate kinase, and nucleotide diphosphokinase. Alternatively, adenosine can be degraded to adenine, hypoxanthine, and inosine, which are normally excreted by cells. Little radioactivity is associated with these compounds within the cell. The observed labeling of IMP is consistent with the existence of the enzyme AMP deaminase, which can initiate degradation of AMP to hypoxanthine or divert the nucleotide base to synthesis of guanosine monophosphate. No detectable labeling of NAD or adenine was observed in this culture, which is consistent with the low concentration of these compounds within cells. Thus, the pattern of intracellular labeling resulting from isotopic incubation with $\left[{ }^{3} \mathrm{H}\right]$ adenosine is consistent with known metabolic pathways and transport mechanisms. This pattern is also similar to that observed by Zimmerman et al. (1979) after $\left[{ }^{3} \mathrm{H}\right]$ adenosine loading of electroplax tissue blocks and synaptosome preparations. In comparing the relative amounts of radioactivity associated with each compound analyzed by thin-layer chromatog- 

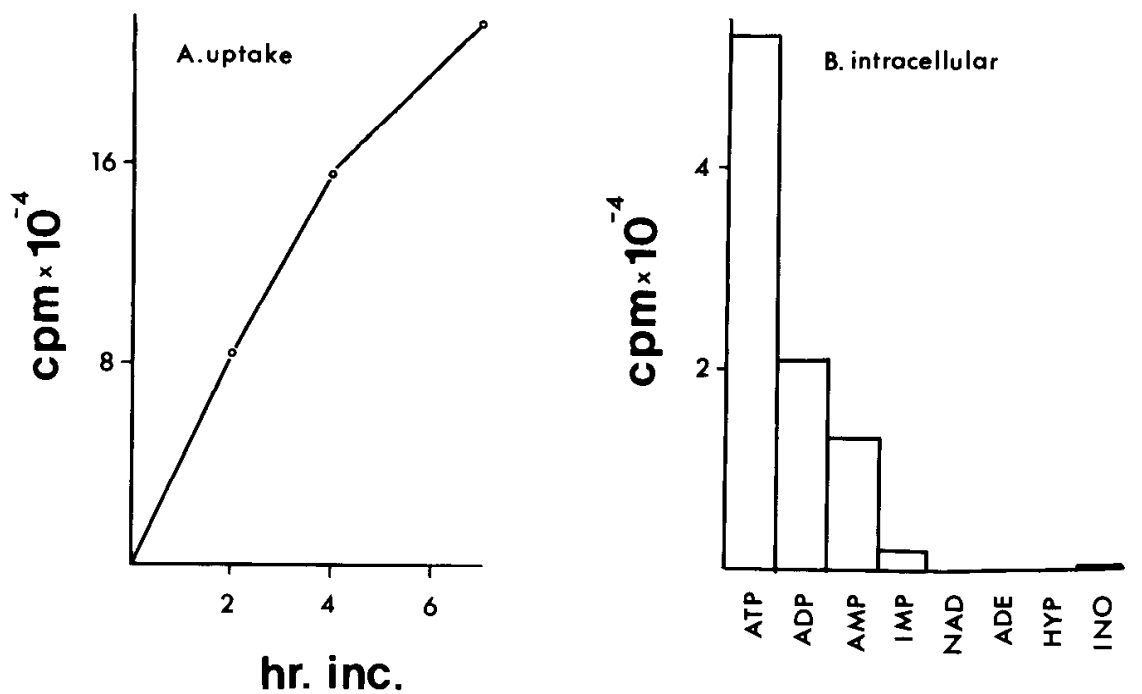

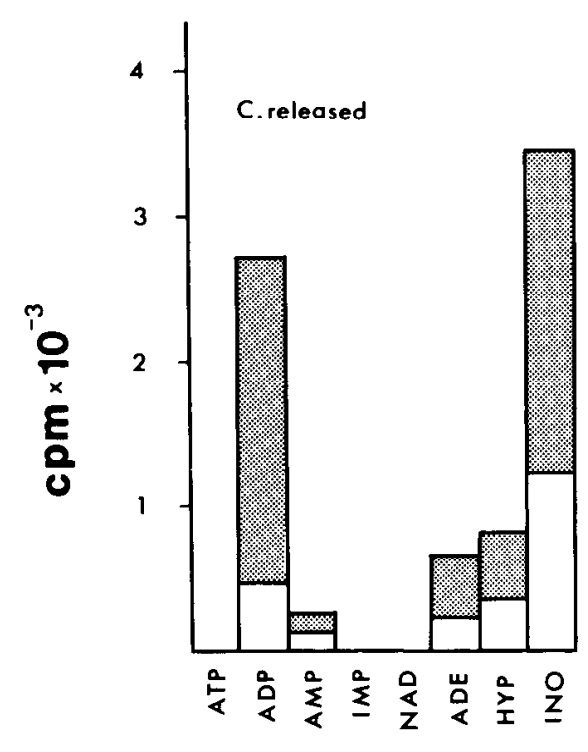

Figure 1. Uptake and incorporation and release of [ $\left.{ }^{3} \mathrm{H}\right]$ adenosine and metabolites. Uptake and incorporation of [ ${ }^{3} \mathrm{H}$ ]adenosine by cultured sympathetic neurons are shown in $A$ and $B$. $C$ shows radioactivity (migrating with the indicated standards during thin-layer chromatographic analysis) found in culture supernatants after $5 \mathrm{~min}$ of incubation in nondepolarizing, $\mathrm{Ca}^{++}$-containing saline (height of open bars) and in depolarizing, $\mathrm{Ba}^{++}$-containing saline (height of stippled bars). The proportion of stippling indicates radioactivity released above nondepolarized levels. These data were obtained from one $12{ }^{1 / 2}-$ week-old serum-containing culture. ATP, adenosine $5^{\prime}$-triphosphate; ADP, adenosine $5^{\prime}$-diphosphate; AMP, adenosine $5^{\prime}$-monophosphate; IMP, inosine $5^{\prime}$-monophosphate (a small amount of CAMP may be present in the AMP and MP spots); NAD, nicotinamide adenine dinucleotide (adenine comigrates with this marker); ADE, adenosine; HYP, hypoxanthine; INO, inosine.

raphy, it has been assumed that the specific activity of each compound is similar. This assumption is based on the extremely rapid equilibration of these pools observed in numerous tissues (Fox and Kelly, 1978), including rabbit vagus nerve (Maire et al., 1982), guinea pig taenia coli (Su et al., 1971), and electroplax (Zimmerman et al., 1979).

Chromatographic analysis of culture supernatant from low potassium and high potassium incubations of the same culture are shown in Figure $1 \mathrm{C}$. The results of each of two 5 -min incubations in isotonic saline containing $5 \mathrm{~mm} \mathrm{~K}^{+}$and $\mathrm{Ca}^{++}$as the only divalent cation were quite similar and were averaged for graphical representation (Fig. $1 C$, height of open bars). In a third 5-min incubation, the culture was depolarized with isotonic saline containing $54 \mathrm{mM} \mathrm{K}^{+}$and $\mathrm{Ba}^{++}$ instead of $\mathrm{Ca}^{++}$to enhance exocytotic release. In Figure $1 \mathrm{C}$, the total radioactivity found in the culture supernatant after depolarization is indicated for each compound by the total height of the stippled and open bars. The amount of each compound released during depolarization in excess of release into nondepolarizing medium is indicated by the stippled portion of cach bar. During depolarization in the presence of $\mathrm{Ba}^{++}$, significantly larger amounts of ADP, AMP, adenosine, hypoxanthine, and inosine were released from the neurons than during nondepolarizing incubations. The increase in adenine nucleotide release during depolarization is greater than 5 -fold. Thus, it appears that depolarization can clicit sccretion of purine nucleotides, nucleosides, and bases from these neurons.

The effects of three different divalent cations on the depolarizationstimulated release of $\left[{ }^{3} \mathrm{H}\right]$ adenosine metabolites is shown in Figure 2. Figure $2 A$ shows the results of depolarization with $54 \mathrm{~mm} \mathrm{~K}^{+}$in the presence of $\mathrm{Ca}^{++}$ion. Compared to the result obtained in the presence of $\mathrm{Ba}^{++}$, shown in Figure $2 \mathrm{~B}, \mathrm{Ca}^{++}$supports the release of less radioactivity overall and of less adenine nucleotide in particular. Together, $\mathrm{Ba}^{++}$and high potassium evoked release of all three adenine nucleotides, while the culture depolarized with high potassium in the presence of $\mathrm{Ca}^{++}$released a smaller amount of AMP and degradation products. In Figure 2C, the effect of depolarization with high potassium in the presence of $\mathrm{Co}^{++}$on release of $\left[{ }^{3} \mathrm{H}\right]$ adenosine derivatives is shown. No release over nondepolarized levels was observed.
Several differences can be observed in the results shown in Figure $1 C$ and Figure $2 B$, the most striking of which is the depolarizationstimulated release of ATP in one case and not the other. The experiment shown in Figure 2 is the only one of six iri which depolarization-stimulated release of ATP was observed. Other experiments, such as those shown in Figure 1 and Figures 3 to 5 . consistently showed depolarization-stimulated release of ADP and AMP but were not consistent in the fold stimulation observed over nondepolarized levels or in the ratio of AMP to ADP released. This variability may be due in part to differences in amounts of residual $\mathrm{Ca}^{++}$carried over from incubation in nondepolarizing $\mathrm{Ca}^{++}$-containing saline during changeover to depolarizing, $\mathrm{Ba}^{++}$-containing saline. Extracellular ATPase is strongly activated by $\mathrm{Ca}^{++}$(Stefanovic et al., 1976). Variability in the proportion of ATP and ADP release from rat phrenic motor nerve has been observed by Silinsky (1975) and was found to correspond to differences in ATPase activity between preparations. The observed variability between the experiments presented here makes quantitative comparison of release of specific nuclcotidc spccics uncertain; however, nucleotide release was always observed when cultures were depolarized in the presence of $\mathrm{Ca}^{++}$or $\mathrm{Ba}^{++}$.

The relationship between release of norepinephrine and purines was examined using the drug reserpine. Reserpine blocks transport of catccholaminc into transmitter storage vesicles (Iversen, 1967). The results of such an experiment are shown in Figure 3. Figure $3 A$ shows a control culture stimulated with $54 \mathrm{mM} \mathrm{K}^{+}$in the presence of $\mathrm{Ba}^{++}$. Figure $3 B$ shows the result obtained by identical processing of a sister culture which was exposed to $6.7 \mathrm{~mm}$ reserpine phosphate during the last $2 \mathrm{hr}$ of isotopic incubation. The profiles of radioactive compounds released by the drug-treated and untreated cultures are similar for both the low and high potassium incubations. The somewhat lower AMP release by the drug-treated culture is within the range of variation discussed above. Thus, depolarization-stimulated release of $\left[{ }^{3} \mathrm{H}\right]$ adenosine metabolites by these cultures is rescrpinc insensitive.

The cultures studied in the experiments presented thus far were all maintained in serum-containing medium. Cultures grown under these conditions are able to synthesize and accumulate both ace- 


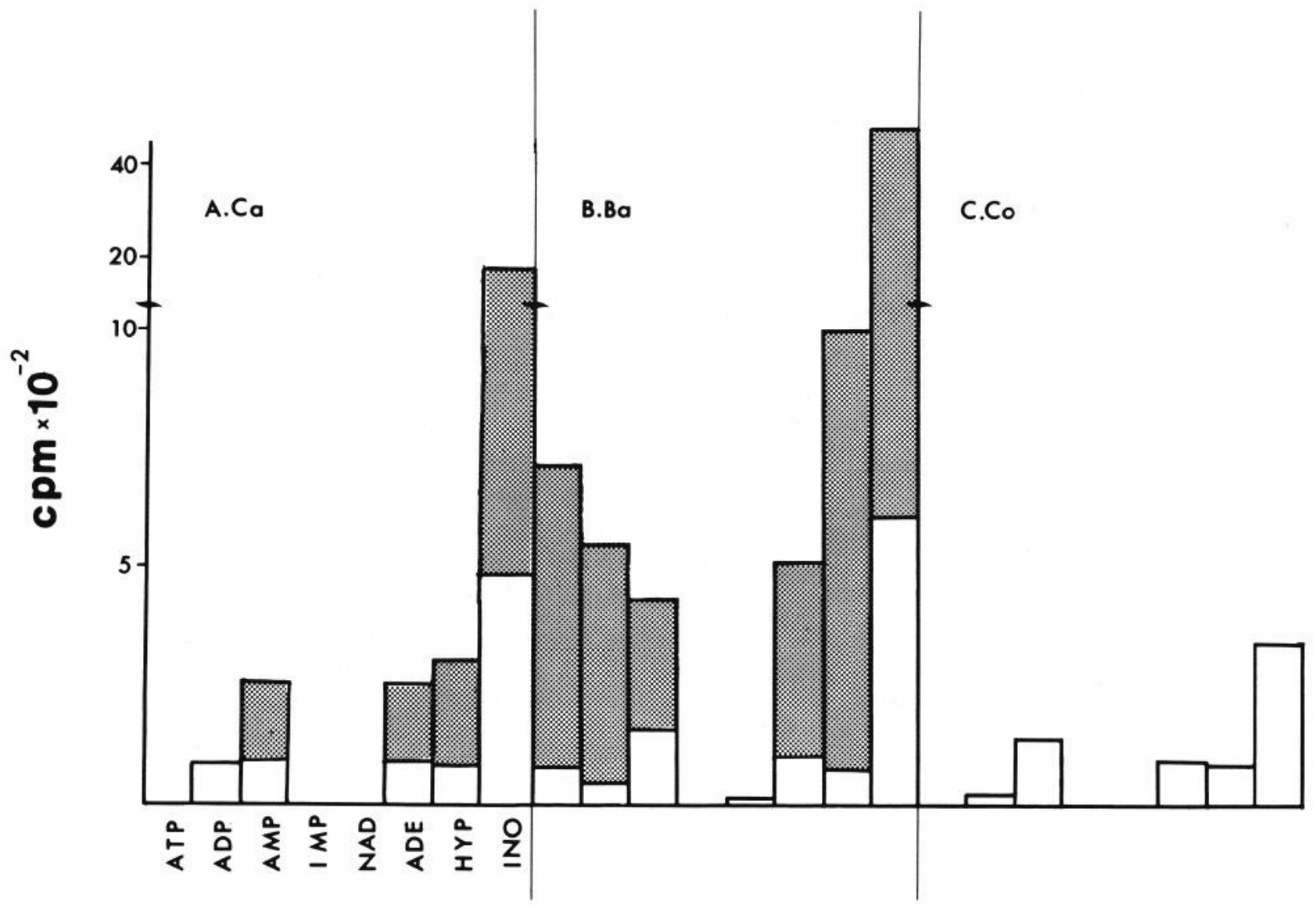

Figure 2. Effect of divalent cations on release of $\left[{ }^{3} \mathrm{H}\right]$ adenosine metabolites. Results of depolarization in saline containing $\mathrm{Ca}^{++}(A), \mathrm{Ba}^{++}(B)$, and $\mathrm{Co}^{++}$ (C) are shown (height of stippled bars). Basal release was determined in nondepolarizing, $\mathrm{Ca}^{++}$-containing saline prior to depolarization (open bars). The metabolites are represented in the same order by the bars in each panel. Abbreviations are as in Figure 1. These data were obtained from three serumcontaining, 3-week-old sister cultures.
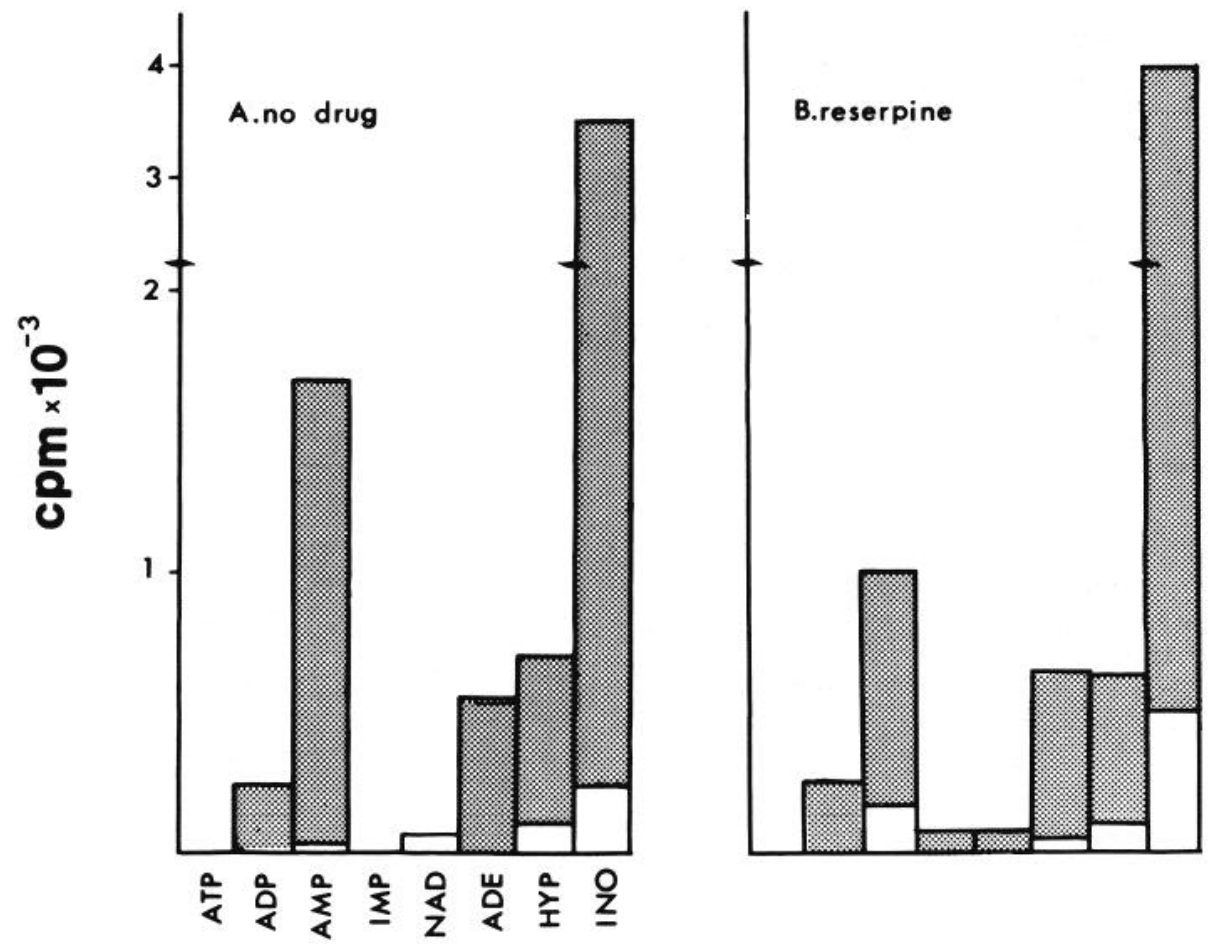

Figure 3. Lack of effect of reserpine on release of $\left[{ }^{3} \mathrm{H}\right]$ adenosine metabolites. Results of depolarization in saline containing $\mathrm{Ba}^{++}$(height of stippled bars) is shown for a control culture $(A)$ and a culture treated with $6.7 \mu \mathrm{M}$ reserpine phos phate (Ciba Pharmaceutical) $(B)$ during the last 2 $\mathrm{hr}$ of isotopic labeling. Basal release was determined in nondepolarizing, $\mathrm{Ca}^{++}$-containing saline (open bars) prior to depolarization. The metabolites are represented in the same order by the bars of each panel. Abbreviations are as in Figure 1. Data were obtained from a pair of $3 \frac{1}{2}$-week old, serum-containing sister cultures. 
tylcholine and catecholamine (Patterson, 1978). Depolarization-stimulated release of $\left[{ }^{3} \mathrm{H}\right]$ adenosine metabolites was also observed from noradrenergic serum-containing cultures maintained in growth medium containing elevated potassium to provide chronic depolarization (Fig. 4).

Neurons grown with defined medium are also noradrenergic (lacovitti et al., 1982; Wolinsky et al., 1985a). Depolarization-stimulated release of $\left[{ }^{3} \mathrm{H}\right]$ adenosine metabolites from serum-free and serum-containing cultures is compared in Figure 5. Although depolarization of both types of culture elicited release of tritiated adenosine, hypoxanthine, and inosine, the serum-free culture did not display a depolarization-stimulated release of labeled adenine nucleotides. The same result was obtained with serum-free cultures maintained with chronic depolarization (data not shown). Thus, depolarization of serum-free cultures appears to separate increased appearance of adenosine, hypoxanthine, and inosine in the medium from that of adenine nucleotides.

\section{Discussion}

The main conclusion which may be drawn from the results reported here is that sympathetic neurons cultured with serum release purine compounds, including nucleotides, in response to depolarization. Serum-free cultures release adenosine, hypoxanthine, and inosine but not adenine nucleotides. The release of these compounds may be unambiguously ascribed to neurons since, in this culture system, antimitotic agents are used to eliminate nonneuronal cells.

Cultured sympathetic neurons are able to take up $\left[{ }^{3} \mathrm{H}\right]$ adenosine from the medium (Fig. 1A) and convert it to intracellular stores of adenine nucleotides (Fig. 1B). When isotopically labeled cultures

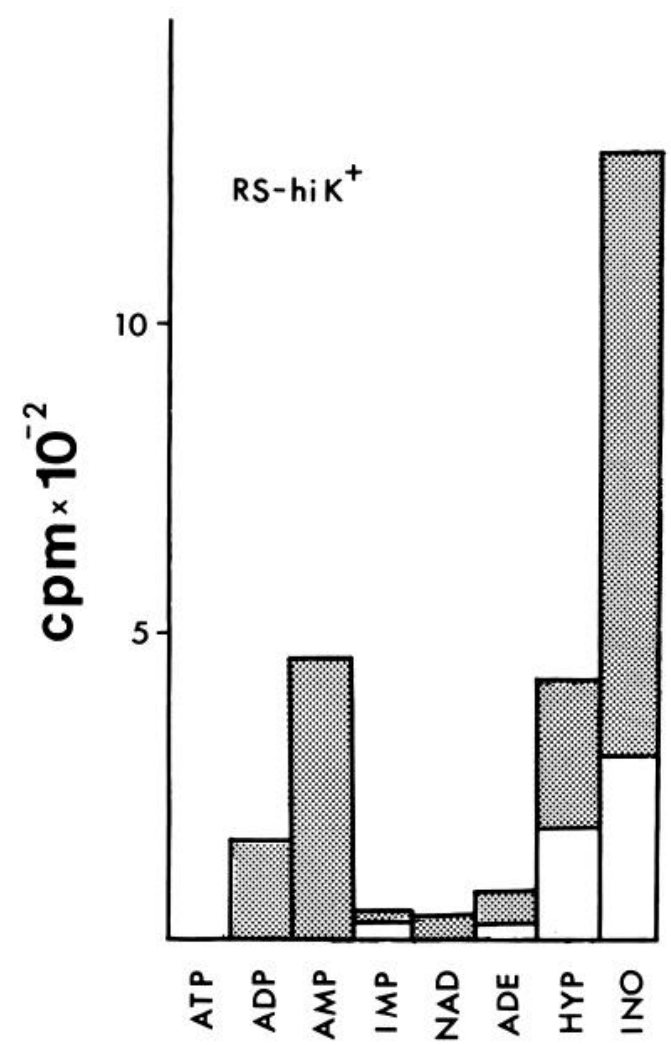

Figure 4. Release of $\left[{ }^{3} \mathrm{H}\right]$ adenosine metabolites by chronically depolarized neurons. Results of depolarization in saline containing $\mathrm{Ba}^{++}$(height of stippled bars) is shown for a 4-week-old serum-containing culture maintained in depolarizing growth medium. Basal release was determined in nondepolarizing, $\mathrm{Ca}^{++}$-containing saline (open bars) prior to depolarization. One day prior to isotopic labeling, the high $\mathrm{K}^{+}$growth medium was replaced with nondepolarizing medium to allow restoration of vesicular pools. Abbreviations are as in Figure 1. are incubated under nondepolarizing conditions, in saline containing $\mathrm{Ca}^{++}$as the only divalent cation, radioactivity appears in the culture medium as adenine nucleotides and as adenosine, inosine, and hypoxanthine. Inosine and hypoxanthine account for most of the radioactivity found in the medium under these conditions. When the neurons are depolarized with $54 \mathrm{mM} \mathrm{K}^{+}$in the presence of either $\mathrm{Ca}^{++}$or $\mathrm{Ba}^{++}$, a large increase in the release of radioactivity occursbetween 2- and 10-fold (Fig. $1 \mathrm{C}$ and Figs. 2 to 5). The majority of this radioactivity is also in inosine and hypoxanthine; however, the proportional increase in the appearance of adenine nucleotides in the incubation medium of serum-containing cultures is at least equal to and, in some cases, is greater than that of adenosine, inosine, and hypoxanthine. Depolarization-stimulated release of ATP by serum-containing cultures has been confirmed by Dr. Koichi Yoshioka using the firefly luciferase assay (personal communication).

The effects of $\mathrm{Ca}^{++}, \mathrm{Ba}^{++}$, and $\mathrm{Co}^{++}$on purine release by sympathetic neurons during depolarization parallels their actions on norepinephrine release. In 5 min during depolarization with high $\mathrm{K}^{+}$ in the presence of $\mathrm{Ca}^{++}$, sympathetic neuron cultures have been observed to release 5 to $10 \%$ of their norepinephrine stores (Wolinsky et al., 1985a). Depolarization in the presence of $10 \mathrm{~mm} \mathrm{Ba}^{++}$ results in enhancement of norepinephrine release by $160 \%$ (Sweadner, 1983). $\mathrm{Co}^{++}$blocks norepinephrine release from sympathetic neuron cultures (Patterson et al., 1976) and depletion of synaptic vesicles, as well as uptake of horseradish peroxidase into synaptic vesicles, which reflects membrane recycling (Buckley and Landis, 1983a). The observed effects of $\mathrm{Ca}^{++}, \mathrm{Ba}^{++}$, and $\mathrm{Co}^{++}$on release of $\left[{ }^{3} \mathrm{H}\right]$ adenosine metabolites are consistent with the release of this radioactivity originating from a neurosecretory event. Such a hypothesis raises the question of whether the source of the released purine compounds is the interior of neurosecretory vesicles or whether they derive from other $\mathrm{Ca}^{++}$-sensitive processes which are related to transmitter release.

Elevated metabolic activity in neuronal terminals during extended periods of transmitter release would be expected to result in release of adenosine and its degradation products rather than adenine nucleotides. Unlike adenine nucleotides, adenosine, inosine, and hypoxanthine easily pass through the plasma membrane. Thus, metabolic activity is a possible source of adenosine and its degradation products released during depolarization; however, it cannot satisfactorily account for release of adenine nucleotides. Vesicular release is a more attractive mechanism for the release of adenine nucleotides because it circumvents the plasma membrane permeability barrier.

Two hypotheses will be considered: (1) that the depolarizationstimulated nucleotide release observed in sympathetic neuron cultures is due to an exocytotic mechanism similar to that for release of neurotransmitters such as norepinephrine and acetylcholine and that release of adenosine, inosine, and hypoxanthine is mostly due to increased energy utilization and metabolism during extended release periods, resulting in turnover of nucleotides; or (2) that all of the labeled purine compounds found in the medium following depolarization are a result of exocytotic release of adenine nucleotides succeeded by extensive extracellular degradation. A variant of this possibility is that secretory vesicles contain all the purine species observed and release them simultaneously. Extracellular degradation would then further modify the proportions of each species observed. In both hypotheses, intracellular adenine nucleotides would be the precursors to all released compounds, since intracellular stores of adenosine and purine bases are insignificant. The main distinction between the two hypotheses is the site at which nucleotide degradation is supposed to occur: the first hypothesis posits intracellular degradation followed by efflux of products; the second hypothesis specifies extracellular degradation of exocytotically released nucleotides.

According to the first hypothesis, adenine nucleotide release would occur by a different route from release of adenosine, hypoxanthine, and inosine. Under some circumstances, then, it may be 




Figure 5. Release of $\left[{ }^{3} \mathrm{H}\right]$ adenosine metabolites by neurons grown in defined medium. Results of depolarization in saline containing $\mathrm{Ba}^{++}$are compared for serum-containing $(A)$ and a serum-free $(B)$ sister cultures (height of stippled bars). Basal release was determined in nondepolarizing $\mathrm{Ca}^{++}$ containing saline (open bars). The metabolites are represented in the same order by the bars in each panel. Abbreviations are as in Figure 1. These cultures were $2 \frac{1}{2}$ weeks old.

possible to separate release of the two types of purine. This is the case for cultures maintained in defined medium. Depolarization of these neurons causes release of labeled adenosine, hypoxanthine, and inosine but not of adenine nucleotides (Fig. 5). This might result from a lack of the vesicle type from which adenine nucleotides are normally released or from failure to load such vesicles with adenine nucleotides. Depolarization-stimulated norepinephrine release has been found to occur in these cultures (Wolinsky et al., 1985a), and, according to the first hypothesis, nonphosphorylated purines would be excreted as by-products of the energy expenditure required to support extended release of catecholamine. An alternative possibility is that serum-free cultures may possess greater degradative capacity than serum-containing cultures and that the failure to observe adenine nucleotides in the incubation medium after depolarization of serum-free cultures may be due to more rapid dephosphorylation and deamidation. Cultured rat dorsal root ganglion cells are another example in which depolarization stimulates release of adenosine, inosine, and hypoxanthine but not of adenine nucleotides (Dr. K. Yoshioka, personal communication). Pull and Mcllwain (1973) have concluded that adenine nucleotide release and that of adenosine, inosine, and hypoxanthine from stimulated guinea pig neocortex arise from different sources based on their differential sensitivity to tetrodotoxin; adenine nucleotide release was not affected by the same concentration of drug which blocked both adenosine, inosine, and hypoxanthine release and stimulation-dependent lactate production.

Extracellular degradative capacity is related to the second hypothesis. Enzyme activities necessary for degradation of ATP to hypoxanthine (ATPase, 5' -nucleotidease, adenosine, and AMP deaminases) have been identified as ectoenzymes on several nervous system-derived cells, cell lines, and other tissues (Trams and Lauter, 1974; Manery and Dryden, 1979). These enzymes are bound to the plasma membrane and are active in situ on the extracellular side. Degradation of exogenous ATP to inosine and hypoxanthine has been observed in several preparations, including electroplax tissue and synaptosomes (Zimmerman et al., 1979) and rabbit vagus nerve (Maire et al., 1982). The data required to determine whether extracellular degradative activity in sympathetic neuron cultures is adequate to convert enough released adenine nucleotide to account for the observed quantities of adenosine, inosine, and hypoxanthine within the 5-min incubation period have not been obtained.

The type of vesicle from which the purine may be released is unclear. The large, opaque vesicles identified as purinergic by Robinson et al. (1971) are not present in cultured sympathetic neurons (Johnson et al., 1980; Buckley and Landis, 1983b). Both adrenergic (Aberer et al., 1979) and cholinergic (Dowdall et al., 1974; Wagner et al., 1978) vesicles from other tissues have been determined to contain ATP. Small granular adrenergic vesicles, however, contain very low levels of ATP (Fried, 1980). Dual-function cultures, such as those studied here, contain both small granular vesicles and clear vesicles. Noradrenergic cultures maintained by chronic depolarization contain a higher percentage of catecholamine storage vesicles and relatively few clear vesicles, while clear vesicles predominate in cholinergic cultures treated with heart cell conditioned medium (Landis, 1980). Both types of cultures release adenine nucleotides in response to depolarization (Figs. 1C and 4). The failure of serum-free cultures to release adenine nucleotides and their unexplained high frequency of clear vesicles are an interesting but puzzling correlation.

In other systems, drugs have been useful in testing hypotheses concerning costorage of ATP with conventional neurotransmitters. Silinsky (1975) found that ATP released from stimulated rat phrenic motor nerve terminals was related to the quantal size of acetylcholine release, manipulated experimentally in various ways, including application of hemicholinium. Costorage of ATP with norepinephrine in small granular vesicles has been determined biochemically (Aberer et al., 1979; but see Fried, 1980) and is suggested by the abolition of purinoceptor-mediated neurogenic excitation of guinea pig bladder after chemical sympathectomy with 6-hydroxydopamine (Sneddon et al., 1982; Westfall et al., 1983). Reserpine treatment of sympathetic neuron cultures did not impair adenine nucleotide release, however. This could result from nucleotide storage in noradrenergic vesicles being independent of the reserpine-sensitive catecholamine uptake system or from nucleotide storage in a separate vesicle population. No association between adenine nucleotide release and vesicle type has been established by these experiments.

The reserpine insensitivity of biochemically observed purine release parallels that of the physiological responses (Dr. S. Matsu- 
moto, personal communication). Reserpine treatment sufficient to abolish previously observed excitatory synaptic interactions with heart cells (noradrenergic function) did not impair the atropineinsensitive inhibitory response. Neurons exerting purinergic effects on heart cells have been found to express varying degrees of cholinergic and adrenergic effects as well. As in the biochemical studies with mass cultures, the microcultures do not display a striking correlation of degree of purinergic function with transmitter choice with respect to acetylcholine and catecholamines.

Whatever the details of the mechanism, it is clear that increased amounts of both adenine nucleotide and adenosine appear in the medium during depolarization of serum-containing sympathetic neuron cultures. Previously published (Potter et al., 1983) and forthcoming (E. J. Furshpan, D. D. Potter, and S. Matsumoto, manuscript in preparation) accounts of electrophysiological analysis of interactions between single sympathetic neurons and cardiac myocytes in culture have established a framework of evidence for purinergic transmission with which the characteristics of biochemically observed release can be compared. Both adenine nucleotides (ATP is most potent) and adenosine elicit inhibitory responses from heart cells when directly applied. After electrical stimulation of neurons in microcultures, the heart cells show atropine-insensitive responses similar to those to directly applied purine. Both methylxanthines, which block adenosine receptors in other tissues, and exogenously applied adenosine deaminase, which is supposed to be inactive on nucleotides, eliminated the inhibitory synaptic interactions in some, but not all, cases in which purinergic function was observed. Since adenine nucleotides and their receptor would not be affected by these treatments, the residual inhibitory effect may be due to adenine nucleotides. The biochemically observed release of both adenosine and adenine nucleotides is consistent with this pharmacology. Electrophysiological studies of serum-free cultures, which release detectable amounts of adenosine but not adenine nucleotides, could be useful in distinguishing the effects of these two types of molecule on cultured heart myocytes.

The demonstration that cultured sympathetic neurons take up, store, and release (in a depolarization-dependent, $\mathrm{Ca}^{++}$-sensitive manner) purine compounds complements electrophysiological evidence for purinergic transmission being part of the transmitter repertoire of cultured sympathetic neurons. Since serum-free cultures differ from serum-containing cultures in failing to release detectable adenine nucleotides during depolarization, it is possible that they do not fully share the capability for purinergic transmission. Perhaps development of this feature, like that of acetylcholine production, depends on factors in serum or conditioned medium and can be induced under serum-free conditions by treatment with appropriate additives.

\section{References}

Aberer, W., R. Stitzel, H. Winkler, and E. Huber (1979) Accumulation of $\left[{ }^{3} \mathrm{H}\right]$ ATP in small dense core vesicles of superfused rat vas deferentia. J. Neurochem. 33: 797-801.

Buckley, K. M., and S. C. Landis (1983a) Morphological studies of neurotransmitter release and membrane recycling in sympathetic nerve terminals in culture. J. Neurocytol. 12: 93-116.

Buckley, K. M., and S. C. Landis (1983b) Morphological studies of synapses and varicosities in dissociatcd cell cultures of sympathetic neurons. $\mathrm{J}$. Neurocytol. 12: 67-92.

Burnstock, G. (1972) Purinergic nerves. Pharmacol. Rev. 24: 509-581.

Burnstock, G., T. Cocks, R. Crowe, and L. Kasakov (1978) Purinergic innervation of the guinea pig urinary bladder. Br. J. Pharmacol. 63: 125138.

Dowdall, M. J., A. F. Boyne, and V. Whittaker (1974) Adenosine triphosphate: A constituent of cholinergic synaptic vesicles. Biochem. J. 140: 1-12.

Fox, I. H., and W. N. Kelly (1978) The role of adenosine and $2^{\prime}$-deoxyadenosine in mammalian cells. Annu. Rev. Biochem. 47: 655-686.

Fried, G. (1980) Acta Physiol. Scand. Suppl. 493: 1-28.

Furshpan, E. J., D. D. Potter, and S. C. Landis (1981) On the transmitter repertoire of sympathetic neurons in culture. Harvey Lect. 76: 149-191.
Hawrot, E., and P. H. Patterson (1979) Long-term culture of dissociated sympathetic neurons. Methods Enzymol. 58: 5/4-584.

lacovitti, L., T. H. Joh, D. H. Park, and R. P. Bunge (1981) Dual expression of neurotransmitter synthesis in cultured autonomic neurons. J. Neurosci. 1: $685-690$.

lacovitti, L., M. I. Johnson, T. H. Joh, and R. P. Bunge (1982) Biochemical and morphological characterization of sympathetic neurons grown in a chemically defined medium. Neuroscience $7: 2225-2239$.

Iversen, L. (1967) The Uptake and Storage of Noradrenaline in Sympathetic Nerves, Cambridge University Press, Cambridge, England.

Johnson, M., C. D. Ross, M. Myers, S. L. Spitznagel, and R. P. Bunge (1980) Morphological and biochemical studies on the development of cholinergic properties in cultured sympathetic neurons. I. Correlative changes in choline acetyltransferase and synaptic vesicle cytochemistry. J. Cell. Biol. 84: 680-691.

Landis, S. C. (1980) Developmental changes in the neurotransmitter properties of dissociated sympathetic neurons: A cytochemical study of the effects of medium. Dev. Biol. 77: 349-361.

Maire, J. C., J. Medilanski, and R. W. Straub (1982) Uptake of adenosine and release of adenine derivatives in mammalian non-myelinated nerve fibres at rest and during activity. J. Physiol. (Lond.) 323: 580-602.

Manery, J. F., and E. E. Dryden (1979) Ectoenzymes concerned with nucleotide metabolism. In Physiological and Regulatory Functions of Adenine Nucleotides, H. P. Baer and G. I. Drummond, eds., pp. 323-340, Raven Press, New York.

Patterson, P. H. (1978) Environmental determination of autonomic neurotransmitter functions. Annu. Rev. Neurosci. 1: 1-17.

Patterson, P. H., and L. L. Y. Chun (1977) The induction of acetylcholine synthesis in primary cultures of dissociated rat sympathetic neurons. I. Effects of conditioned medium. Dev. Biol. 56: 263-280.

Patterson, P. H., L. F. Reichardt, and L. L. Y. Chun (1976) Biochemical studies on the development of primary sympathetic neurons in cell culture. Cold Spring Harbor Symp. Quant. Biol. 40: 389-397.

Potter, D. D., E. J. Furshpan, and S. C. Landis (1983) Transmitter status in cultured rat sympathetic neurons: Plasticity and multiple function. Fed. Proc. 42: 1626-1632.

Pull, I., and H. Mcllwain (1972) Adenine derivatives as neurohumoral agents in the brain. Biochem. J. 130: 975-81.

Pull, I., and H. Mcllwain (1973) Output of $\left[{ }^{14} \mathrm{C}\right]$ adenine nucleotides and their derivatives from cerebral tissues. Biochem. J. 136: 893-901.

Reibel, D. K., and M. J. Rovetto (1978) Separation of myocardial purine nucleosides and nucleotides by one-dimensional thin layer chromatography. J. Chromatogr. 161: 406-409.

Robinson, P. M., J. R. McLean, and G. Burnstock (1971) Ultrastructural identification of nonadrenergic inhibitory nerve fibres. J. Pharmacol. Exp. Ther. 179: 149.

Silinsky, E. M. (1975) On the association between transmitter secretion and the release of adenine nucleotides from mammalian motor nerve terminals. J. Physiol. (Lond.) 247: 145-162.

Sneddon, P., D. P. Westfall, and J. S. Fedan (1982) Cotransmitters in the motor nerves of the guinea pig vas deferens: Electrophysiological evidence. Science 218: 693-695.

Stefanovic, V., M. Ledig, and P. Mandel (1976) Divalent cation-activated ecto-nucleoside triphosphatase activity in nervous system cells in tissue culture. J. Neurochem. 27: 799-805.

Stone, T. W. (1981) Physiological roles for adenosine and adenosine $5^{\prime}$ triphosphate in the nervous system. Neuroscience 6: 523-555.

Sweadner, K. J. (1981) Environmentally regulated expression of soluble extracellular proteins of sympathetic neurons. J. Biol. Chem. 256: 40634070.

Sweadner, K. J. (1983) Post-translational modification and evoked release of two large surface proteins of sympathetic neurons. J. Neurosci. 3: 25042517.

Su, C., J. A. Bevan, and G. Burnstock (1971) $\left[{ }^{3} \mathrm{H}\right]$ Adenosine release during stimulation of enteric nerves. Science 173: 336-338.

Trams, E. G., and C. J. Lauter (1974) On the sidedness of plasma membrane enzymes. Biochim. Biophys. Acta 345: 180-197.

Wagner, J. A., S. S. Carlson, and R. B. Kelly (1978) Chemical and physical characterization of cholinergic synaptic vesicles. Biochemistry 17: 11991206.

Walicke, P. A., R. B. Campenot, and P. H. Patterson (1977) Determination of transmitter function by neuronal activity. Proc. Nati. Acad. Sci. U. S. A. 74: $5767-5771$.

Westfall, D. P., J. S. Fedan, J. Colby, G. K. Hogaboom, and J. P. O'Donnell 
(1983) Evidence for a contribution by purines to the neurogenic response of the guinea pig urinary bladder. Eur. J. Pharrm. 87: 415-422.

Wolinsky, E., and P. H. Patterson (1983) Tyrosine hydroxylase activity decreases with induction of cholinergic properties in cultured sympathetic neurons. J. Neurosci. 3: 1495-1500.

Wolinsky, E. J., and P. H. Patterson (1985) Rat serum contains a developmentally regulated cholinergic inducing activity. J. Neurosci. 5: 1509-1512. Wolinsky, E. J., S. C. Landis, and P. H. Patterson (1985a) Expression of noradrenergic and cholinergic traits by sympathetic neurons cultured without serum. J. Neurosci. 5: 1497-1508.

Wolinsky, E. J., P. H. Patterson, and A. L. Willard (1985b) Insulin promotes electrical coupling between cultured sympathetic neurons. J. Neurosci. 5 : 1675-1679.

Zimmerman, H., M. J. Dowdall, and D. A. Lane (1979) Purine salvage at the cholinergic nerve endings of the Torpedo electric organ: The central role of adenosine. Neuroscience 4: 979-993. 